\title{
A pilot assessment of pre-k and elementary physical activity opportunities in a rural Georgia county
}

\begin{abstract}
Almost $90 \%$ of students do not meet the national recommendations for physical activity Research conducted to determine physical activity levels among children under the age of 11 is limited, yet necessary, to decrease the elevating rates of chronic disease. This pilot study aimed to assess current physical activity opportunities in a rural Georgia county to determine $^{1}$ if 60 minutes of physical activity is provided daily ${ }^{2}$ the barriers/facilitators associated with increasing physical activity in school; and ${ }^{3}$ suggestions for most effective methods to increase physical activity during the school day. Using an online survey adapted from the School Health Policies and Practices Study Physical Education School and Classroom questionnaires (National Center for Chronic Disease and Health Promotion), 53 school board members, principals and teachers in a rural Georgia County were surveyed and 18 interviewed. Findings showed that at least 60 minutes of physical activity per day are neither required, nor achieved by children in pre-kindergarten through fifth grade. Barriers to providing the recommended levels include lack of resources in various areas, including administrative support and assistance in developing lesson plans that incorporate physical activity. According to participants, the most effective method to increase physical activity for the school system is through classroom-based physical activity curricula Incorporating physical activity into the core subjects that students engage in daily, such as math and science, will increase the daily activity levels and allow children to meet the recommendations of 60minutes of physical activity per day as described by the American College of Sports Medicine and the American Heart Association. Integration would also facilitate movement towards the Healthy People 2020 goals and objectives related to school policies requiring daily physical education for all students. Further studies should be conducted to determine student, parent and school administration awareness of school related physical activity.
\end{abstract}

Keywords: physical activity, elementary school physical activity requirements, classroom based physical activity
Volume 2 Issue 3 - 2015

\author{
Cheryl LR Gaddis \\ Mercer University College of Health Professions, USA
}

Correspondence: Cheryl LR Gaddis, Assistant Professor of Practice, Mercer University College of Health Professions, 1550 College Street Macon, GA 3/207, USA, Tel 47830I5322, Email gaddis_cr@mercer.edu

Received: January 21, 2015 | Published: May 09, 2015
Abbreviations: YRBSS, youth risk behavioral surveillance system; CDC, centers for disease control; SHPPS, school health policies and practices study; SRQ, sub research questions; AYP, annual yearly progress

\section{Introduction}

Engaging in consistent physical activity is important for maintaining good health and preventing disease and death. However, many children face barriers when trying to engage in adequate levels of physical activity, leading to the development of obesity and chronic illnesses. The Youth Risk Behavioral Surveillance System (YRBSS) is conducted annually to monitor specific categories of health risk behaviors, including physical activity and obesity, among youth and young adults. Results show that during the seven days preceding the survey, $81.6 \%$ of children were not physically active for at least 60 minutes per day on all seven days and only one-third attended physical education class. ${ }^{1}$ Additionally, Healthy People 2020 documents that only $18.4 \%$ of adolescents met current physical guidelines for aerobic physical activity in $2009 .{ }^{2}$ Contributing factors to the decrease in physical activity among youth include reduced physical education at school, increased homework loads, campus vending machines, television, larger portion sizes, fast food restaurants and video games among many others. ${ }^{3}$ Therefore, the responsibility for increasing physical activity not only exists at the individual level, but also at the institutional and systematic levels where the school system exists.

Although the current recommendation for youth by the American College of Sports Medicine ${ }^{4}$ consists of intense cardio for thirty minutes a day, five days a week, many youth fall short of this goal. Opportunities to engage in physical activity at school are available through extracurricular activities; however, not all students participate in extracurricular activities. All students are required to participate in a physical education course; however, the opportunity for physical activity is not always available within the physical education curriculum. As of 2006, only $3.8 \%$ of public and private elementary schools required daily physical education for all students. ${ }^{5}$ Historically, the school environment has been thought of as the principle means through which children engage in the majority of physical activity. ${ }^{2}$ However, the decrease in required physical activity in school leads to insufficient amounts of physical activity overall. Only 17 to $22 \%$ of elementary schools offer daily physical education with a cumulative duration of about 85 to 98 minutes per week ${ }^{5}$ significantly below the recommended amount of physical activity by the American College of Sports Medicine.

While local districts are required to set programming goals and conduct evaluations, no federal law exists to require physical 
education provisions for students nor any incentives for offering physical education programs. This lack of national requirement results in children in many school districts not achieving adequate amounts of physical activity during the school day. Despite the lack of requirements on the federal level, programs have been put into place to increase physical activity among children. For example, the National Association for Sport and Physical Education publishes standards which define quality physical education for elementary through high school utilizing a comprehensive school physical activity program. ${ }^{6}$ These standards accentuate the daily and minimum time requirements for physical activity that students should meet. Programs such as this exist at national, state and local levels; however, school districts are not required to participate in these programs.

The Stage Theory of Organizational Change, a theory which helps to explain the different stages organizations pass through to recognize the need for change, then plan and implement new ideas, programs or policies, served as the theoretical foundation for this study. The Stage Theory of Organizational Change, originally conceived by Lewin, proposes that organizations must pass through stages with a specific set of strategies for each stage. ${ }^{7}$ The Awareness Stage seeks to involve management and other personnel in awareness-raising activities to recognize that a problem exists. The Awareness Stage of the Stage Theory of Organizational Change was used in this study to involve school system administration and staff (Board of Education members, principals and teachers) in recognizing and analyzing a problem of insufficient amounts of physical activity engaged in by elementary school aged children in order to suggest and evaluate a solution. The results from the study were presented to administration and staff to inform them of decreased levels of physical activity within the school system. The Adoption Stage provided an opportunity for process consultation to inform management and personnel of the components involved in the adoption of new policies or directives. ${ }^{7}$ For this study, the Adoption Stage was used to inform the school system personnel of various types of interventions that would be appropriate for adoption to increase physical activity levels based on the information provided from the surveys and interviews.

Research indicates that most youth do not participate in the recommended daily amount of physical activity. As a result, more children are becoming overweight and obese than ever before. There are many points of impact to increase the level of physical activity among youth. The individuals can make personal behavioral change and parents can positively influence their children on the interpersonal level to engage in physical activity. However, it seems that schools are the ideal setting for encouraging children to engage in more physical activity. As the students spend a third of their day in the school environment, the schools can adopt policies and implement programs that allow them to provide health education and various opportunities for physical activity throughout the day. By working with students, parents and government, schools can encourage children to become physically active in an effort to decrease increasing obesity rates. The objectives of this study were to assess the current physical activity opportunities to determine if 60 minutes of physical activity is provided daily; to identify the barriers/facilitators associated with increasing physical activity in school; and obtains suggestions for the most effective method to increase physical activity for the public school system.

\section{Materials and methods}

A pilot study was conducted in a rural Georgia county in February 2012. Of the 236 county school system employees, a sample of 53 principals, teachers and board members were surveyed electronically and 18 interviewed face-to-face. The eligibility requirements for participation in the survey and interviews included currently serving as a principal/director, assistant principal/director, teacher, paraprofessional, school nurse, or elementary curriculum coordinator in the pre-kindergarten center or elementary schools, or as a Board of Education member of the school system. Sample size was determined through the method of stratified sampling. Strata were identified based on the professional level within the school system (board of education, school administration, teachers/paraprofessionals). Once the strata were determined, random sampling was used to select a sample size to reasonably represent the populations. The survey for this study was developed by adapting questions from the 2006 SHPPS Physical Education School Questionnaire and the Physical Education Classroom Questionnaire that were found to be pertinent to this study. Statistical analysis was performed for descriptive frequencies using SPSS version 17.0 for Windows. Participants who provided mailing address information for receiving an incentive were mailed ten dollars after completing their survey.

The quantitative data analysis revealed areas requiring further elaboration and exploration of reasons for decreased physical activity. Interview questions were developed based on the identified gaps in quantitative data to gain additional insight and themes regarding the barriers and facilitators to physical activity in schools and to determine the most effective methods for increasing physical activity as identified by the participants. Individuals were randomly selected from the survey participants to participate in the interviews. Interviews were conducted until theoretical saturation was reached. The interviewer read the questions while audio recording responses along with written notes. Interviews were transcribed and analyzed using the MAXQDA qualitative data analysis program. Participants received a \$25 cash incentive for participating. Informed consent was secured from each participant prior to eliciting information. Participants were informed of their right to withdraw from the study or to refuse to answer any question. Anonymity was maintained by detaching address information from the survey responses and assigning identification numbers to the interview participants. IRB approval was obtained from Mercer University's Institutional Review Board.

\section{Results}

Of the 53 surveys completed, five were removed because they did not include answers to questions regarding the actual amount of physical activity provided during the school day, leaving 48 utilizable surveys. Only $89.6 \%$ of the respondents indicated a specific role in the school system (Table 1). Those who did not indicate a specific role were associated with grades 5-6. The majority of the respondents (50\%) taught grades 4-5, followed by grades K-3 (42\%), prekindergarten (4\%) and the Upson-Lee Board of Education (4\%). All grades, Pre-K-5 and administrative levels were represented in the survey. However, there were no responses from school nurses and curriculum coordinators.

The first research question asked, "Do the current physical activity opportunities within the school system provide the recommended amount of physical activity for elementary school age children?" The themes from this question focused on the grade level and number of days and minutes students are required to participate in physical activity while at school. Descriptive statistics revealed that all survey participants $(100 \%)$ agreed the students must take physical education as a requirement for graduation or promotion to the next grade at each grade level, pre-kindergarten through 5 th grade. However, only $8 \%$ 
specifically stated that students receive physical education during each grade level 1-5 as shown in Table 2. The number of days that students are required to take physical education was consistently reported among participants as two days per week. Results showed that students are limited by the number of days they are required to take physical education as well as the amount of time they spend in class. Students are only required and scheduled to take the class two days per week for a minimum of 30 minutes each day (Table 3 ). The students may not be active for the entire thirty minutes each day as, according to $65 \%$ of the respondents, the schools require those who attend physical education class to exercise or play sports for at least $50 \%$ of the time (Table 4 ). Therefore, students may only be active for a minimum of 15 minutes during each physical activity session.

Table I Demographic Characteristics by School Location and Role

\begin{tabular}{|c|c|c|c|}
\hline Grade level & Role & $\mathbf{n}$ & Percentage (\%) \\
\hline $\begin{array}{l}\text { Board of } \\
\text { Education }\end{array}$ & School Board & 2 & $4.20 \%$ \\
\hline \multirow[t]{2}{*}{ Pre-Kindergarten } & Director & I & $2.10 \%$ \\
\hline & Pre-K Teacher & 1 & $2.10 \%$ \\
\hline \multirow[t]{7}{*}{ Grades K-3 } & Principal & I & $2.10 \%$ \\
\hline & Kindergarten & 5 & $10.40 \%$ \\
\hline & Ist Grade Teacher & 4 & $8.30 \%$ \\
\hline & Ist Grade Paraprofessional & 1 & $2.10 \%$ \\
\hline & $2^{\text {nd }}$ Grade Teacher & 3 & $6.30 \%$ \\
\hline & $3^{\text {rd }}$ Grade Teacher & 5 & $10.40 \%$ \\
\hline & Unidentified & I & $2.10 \%$ \\
\hline \multirow[t]{6}{*}{ Grades 4-5 } & $4^{\text {th }}$ Grade Teacher & 7 & $14.50 \%$ \\
\hline & $5^{\text {th }}$ Grade Teacher & 7 & $14.50 \%$ \\
\hline & Music Teacher & 2 & $4.20 \%$ \\
\hline & Unidentified & 4 & $8.30 \%$ \\
\hline & Assistant Principal & 2 & $4.20 \%$ \\
\hline & Physical Education Teacher & 2 & $4.20 \%$ \\
\hline $\mathrm{n}=48$ & & & \\
\hline
\end{tabular}

The data also produced responses to opportunities for physical activity outside of physical education. All respondents (97.9\%) except one reported that students do engage in some level of physical activity outside of physical education class. However, $62.5 \%$ reported that students are not required to engage in additional physical activity outside of physical education on any days during the week. The one constant activity through which students achieve additional physical activity is recess when weather permits as reported by $95.8 \%$ of the respondents. Other methods of physical activity during the school day outside of physical education include some dancing in music class $(2.1 \%)$ and centers in the classroom $(2.1 \%)$.
Table 2 Grades in which Children Receive Required Physical Education

\begin{tabular}{lll}
\hline Grade level & Frequency & Percent \\
\hline $\mathrm{I}^{\text {st }}, 2^{\text {nd }}, 3^{\text {rd }}$ & 16 & 33.3 \\
$\mathrm{I}^{\text {st }}, 2^{\text {nd }}, 3^{\text {rd }}, 4^{\text {th }}$ & $\mathrm{I}$ & 2.1 \\
$\mathrm{I}^{\text {st }}, 2^{\text {nd }}, 3^{\text {rd }}, 4^{\text {th }}, 5^{\text {th }}$ & 4 & 8.3 \\
$4^{\text {th }}$ & $\mathrm{I}$ & 2.1 \\
$4^{\text {th }}, 5^{\text {th }}$ & 17 & 35.4 \\
Pre-k & 2 & 4.2 \\
Pre-k, $\left.\right|^{\text {st }}, 2^{\text {nd }}, 3^{\text {rd }}$ & 6 & 12.5 \\
$\mathrm{~N}=48$ & & \\
\hline
\end{tabular}

Table 3 Number of Week Days Physical Education is required

\begin{tabular}{lll}
\hline Number of days & Frequency & Percent \\
\hline 0 Days & 1 & 2.1 \\
I Day & 5 & 10.4 \\
2 Days & 37 & 77.1 \\
3 Days & 2 & 4.2 \\
5 Days & 3 & 6.3 \\
\hline
\end{tabular}

Table 4 Length of Physical Education Session in Minutes

\begin{tabular}{lll}
\hline Session length (minutes) & Frequency & Percent \\
\hline At least 60minutes & 6 & 12.5 \\
At least 30minutes & 42 & 87.5 \\
Total & 48 & 100
\end{tabular}

The interview questions allowed for a more in depth analysis of the content and focus of the physical activity curriculum in order to determine requirements of students while they are in physical education class. The physical activity curriculum is offered in a limited format in order to allow time for other elective classes. The physical education class is offered on a rotating schedule with computer, art and music allowing students to attend P.E. during two 30-45minutes classes per week. Certified physical education teachers teach the classes and the goals of the physical education curricula are to promote good health habits, daily exercise and physical activity. The curriculum is designed to help students develop basic physical abilities in order to get moving and become physically fit to combat childhood obesity. The curriculum also addresses health and safety so not all of the time spent in physical education class is dedicated to being physically active.

\section{Supporting responses}

We rotate CAMP activities (computer, art, PE and music) daily. We have PE two days a week for 45 minutes each day.

Currently we have four specials classes (CAMP - Computer, Art, Music, PE) with two days of P. E. and one of the other classes. Each class is 45 minutes.

The second research question asked, "What are the barriers and facilitators associated with increasing physical activity for students?" Approximately $85 \%$ of the participants stated that staff members at the school are not allowed to use physical activity such as running 
laps or doing push-ups to discipline students for bad behavior but only $67 \%$ reported that they are actually discouraged from doing so. While staff members are not allowed to force students to engage in physical activity for disciplinary measures, they are allowed to exclude students from opportunities to engage in physical activity outside of physical education such as recess (88\%). According to $73 \%$ of respondents, physical education staff has not worked with other teaching staff to address physical activity. In addition, the school has not met with parent organizations $(73 \%)$, family members $(79 \%)$, students $(69 \%)$, or teachers $(77 \%)$ to discuss physical education or acquire suggestions about the physical education components of the curriculum. The school has not discussed incorporating physical activity into other components of the school day outside of physical education (69\%) to facilitate physical activity. Staff also reported that they have not received any staff development on methods to increase the amount of time students are physically active $(92 \%)$ or using physical activity monitoring devices such as pedometers $(94 \%)$.

The survey results only revealed facilitative efforts and barriers as they related to collaboration with staff, parents and students to identify ideas to increase physical activity. Therefore, an interview question was asked to allow participants to identify other facilitators and barriers to providing the recommended amount of physical activity. The main enablers to providing at least 60minutes of physical activity on a daily basis included a structured schedule for physical education, regularly scheduled recess and well-trained staff with equipment and facilities. Informants readily admitted that offering at least 60 minutes of activity daily is not easy. However, they make the most of the days when students are able to engage in physical education and recess. The school buildings are very large so teachers also consider the amount of time spent moving from the classroom to other activities or classes as enhancing the total time spent moving during the day.

\section{Supporting responses}

i. Students have structured P.E. twice a week. Students are encouraged to be engaged in physical activity at recess. It is easier on the days that P. E. is available.

ii. It is not easy because we can do it only two days a week and there is not that much time in the school day to provide physical activity for everyone. Of course, the school is big so they get a lot of walking in during the day.

Inhibitors to providing 60minutes of physical activity daily included limited time for physical activity due to rotation of computer, art, music and physical education. Other inhibitors included the requirements for academic instruction time, pressure to make annual yearly progress (AYP) and classrooms that are small. Funding for the schools is based on the amount of instructional time provided for each student. Therefore, teachers would prefer to spend time providing instruction than allowing students to be physically activity if it means they will receive the necessary funding to staff their positions.

\section{Supporting responses}

i. No Child left behind and in the past AYP. The focus has been on academic reading and math scores. There were many years we were not allowed to have recess and I teach 5th grade. So, that was very difficult to keep the children focused for that long without a break. There has been such high stress on the academics. Also with the change in standards it has taken some of the creativity out of teaching where teachers could have been getting the students up and active. Now there is so much to cover in a certain time that there is no time to get the physical activity in.

ii. The size of the classroom and the size of the students. There is not much room in the classroom. Kids are getting bigger and I have 29 students in my homeroom. So it would be hard to do in the classroom.

The third research question asked, "What is the most effective method to increase physical activity for the school system?" Sixty percent of respondents stated that they provide additional activity through activities such as free play, guided activities and classroombased activities. An interview question was developed to solicit suggestions for other methods to increase physical activity in schools. Ideas to provide increased physical activity for children during the school day focused on incorporating more opportunities at school. The main themes were inclusion of physical activity in the classroom, integration of movement with core academics and provision of additional time during the school day allocated for physical activity. Informants expressed that there are opportunities for additional inclusion of physical activity, despite the survey responses that some teachers provided. However, it would be necessary to maintain control in the classroom while still allowing students to move around the room

\section{Supporting responses}

i. I feel like integrating physical education along with academics is a good way. It's a good way to incorporate movement. We have to find ways to get them up and moving. Many teachers are afraid of that because they don't want the kids to get crazy. But, I feel like the children are more likely to sit still and learn after getting in some wiggle time. You just have to get creative about how you can get them up to move.

ii. I think using some kind of structured program. Maybe every twenty minutes incorporate physical activity into the classroom. But I don't know if it will go over well in the classroom though I do think it is doable for the teachers. If we did 2 or 6minutes every 20 minutes for an hour, I don't think that would detract from academics but help to refocus the kids. Just some type of activity.

\section{Discussion}

\section{Current physical activity opportunities in school}

Do the current physical activity opportunities within the school system provide the recommended amount of physical activity for elementary school age children? This question was asked to determine the awareness level of school system personnel regarding the amount of physical activity the students engage in on a daily basis. The answer to this question based on qualitative and quantitative data collected is no, at least 60 minutes of physical activity opportunities is not provided for the students on a daily basis. While the physical activity opportunities do not provide a minimum of 60minutes of physical activity daily, students do engage in physical activity twice a week in grades pre-kindergarten through five for a minimum of 30minutes during physical education and modestly when other opportunities are available. These results are consistent with those from the Youth Risk Behavioral Surveillance System that showed children were not physically activity for at least 60 minutes per day on all seven days of the week. ${ }^{1}$ 
In addition to physical education, other opportunities for physical activity such as recess were described, although at minimal levels. Ninety-six percent of respondents acknowledge that recess is the one constant activity through which students are usually able to achieve physical activity on a daily basis. However, recess tends to last for only 15-20minutes and is cancelled if weather does not permit or other events take precedence. So on the days that children have physical education and recess, they receive 60 minutes of physical activity, although this may only occur twice a week.

As previous studies indicate, physical activity can be increased by including movement within the classroom outside of physical education class. ${ }^{8}$ Only $12 \%$ of the respondents from this study actually incorporate physical activity into specific courses/subjects. They accomplish this using activities including stretching, energizers and classroom based physical activity programs that are incorporated into subjects such as language, social studies, math, science, music and reading and during testing. Unfortunately, all teachers do not incorporate these additional activities at any given point during the day, nor are they included on a regular basis. Therefore, these activities do not necessarily significantly increase the amount of physical activity that students engage in during the school day. The results are consistent with findings from other studies revealing that schools offer physical activity in insufficient amounts. 5,9

\section{Barriers and facilitators associated with increased physical activity in school}

What are the barriers and facilitators associated with increasing physical activity for students? Several barriers and facilitators were identified through the surveys and interviews based on policies and personal preference among teachers. Teachers reported that recess actually facilitates students engaging in 60 minutes of physical activity on the days that they have recess and physical education. However, if students are being punished by not being able to engage in recess, that contributes to the decreased level of physical activity for that day. These results are similar to those of Vann et al., ${ }^{10}$ which identified taking away playtime for misbehaving as a barrier to physical activity. Maintaining a structured schedule for physical education and recess ensures that students are able to engage in physical activity for at least 60 minutes on the days both are incorporated. When teachers are allowed to take this opportunity away as punishment, it contributes to the difficulty of schools being able to offer at least 60 minutes of physical activity daily.

The policy that physical activity is offered on a rotating basis is also a barrier in that it prevents students from being able to have physical education every day. The requirements for instruction time and pressure to make annual yearly progress help the faculty to ensure students are achieving the academic requirements; but they also decrease the level of physical activity engagement due to classroom time constraints. These barriers are similar to those identified in other studies which indicate that academic achievement goals have forced school districts to reduce or eliminate physical education programs. ${ }^{11-14}$ When funding is tied to test performance, administration and teachers prefer to spend time providing instruction than engaging students in physical activity.

Another barrier that was identified is the lack of collaborative efforts in place to allow input from parents, students, or teachers regarding the amount of physical activity offered at school. Other studies show that effective policies regarding wellness, physical activity and nutrition education goals can been developed ecologically with students, parents, school food service and administrators involved in the development process. ${ }^{15}$ These efforts would ensure input from all groups involved and provide a more representative plan for physical activity engagement. Therefore, it would be more efficient and effective for collaborative efforts among administrators, teachers, students and parents for decisions concerning the increase of physical activity.

\section{Effective methods to increase physical activity in school}

What is the most effective method to increase physical activity for the school system? Survey results showed that $60 \%$ of respondents provided additional physical activity through free play, guided activities and classroom-based activities. The interview provided insight on the best way to increase physical activity as identified by the interviewees. The responses focused on incorporating physical activity into the classroom. They reported that inclusion of physical activity into the classroom outside of physical activity is the best and most effective method to do so. While they were willing to engage in this type of implementation, they were concerned about any interference with academics. They were also concerned about their lack of knowledge regarding these types of classroom-based programs. Feasibility of incorporating classroom-based physical activity would only be possible if they are able to address these issues in addition to previously mentioned barriers. Programs that have been implemented in schools required specific features in order to be successful. These features relate to those issues mentioned by the respondents including identification of staff and resources required for implementation, involvement of stakeholders including teachers, students, parent and other school personnel and training for implementation and evaluation. ${ }^{16}$ Incorporating these features would ensure proper planning and implementation of classroom-based physical activity that all involved are comfortable with for a successful outcome.

\section{Conclusion}

The results of this study reveal the need for recommendations associated with additional research and methods for increasing physical activity within the school system. The results revealed that physical activity opportunities are insufficient for children to engage in 60minutes of physical activity within the school day. The main reason for not achieving at least 60 minutes of physical activity daily relates to policies. The state of Georgia requires a minimum of ninety hours of physical education and health per school year in grades kindergarten through five. ${ }^{17}$ However, there are also policies that students must stay on task academically for a certain amount of time during the school day leading to decreased physical activity time as it rotates with art, music and computer. Additionally, school systems may choose to use any type of curriculum to achieve the physical education requirements. While public health recommendations state that children should achieve at least 60 minutes of physical activity daily, there are no official public health policies in place within the school systems to ensure children actually achieve this amount of physical activity on a daily basis.

This study focused on using Stage Theory of Organizational Change to determine awareness of school personnel and school board members regarding the amount of physical activity engagement among students on a daily basis. The Awareness Stage of the Stage 
Theory of Organizational Change was used to involve school system administration and staff (Board of Education members, principals and teachers) in recognizing and analyzing a problem of insufficient amounts of physical activity engaged in by elementary school aged children in order to suggest and evaluate a solution. Through this stage, school system personnel were involved in the development of possible solutions to address physical activity insufficiency among elementary school children. Possible solutions were also brought forth within the survey and interview questions. The Adoption Stage was used to inform the school system personnel of various types of interventions that would be appropriate for adoption by their organization to increase physical activity levels based on the information provided from the surveys and interviews. The final two stages of the theory, implementation and institutionalization of change stages were not utilized for this particular study. However, these two stages would be used to actually implement a change to the current physical activity requirements based on the results of this study. If adopted, the school system would implement the change and then institutionalize it within the school system through policy.

Further studies should be conducted to determine student and parent awareness of the amount of physical activity engaged in daily while in school. Additionally, implementation of an evidence-based program, such as go for Health, VerbTM or Take 10! into the schools is recommended. The barriers listed by respondents indicated the main inhibitor to increasing physical activity in schools is the amount of time they have to do so. The evidence-based programs are equipped with lesson plans that, not only help teachers incorporate them into the current curriculum, but also make it very easy to achieve additional time for physical activity. Finally, the amount of physical activity that children engage in once they return home should be assessed to determine if the amount of school physical activity and after-school physical activity are actually sufficient to provide a total of 60minutes of physical activity on a daily basis. It is also important to assess the students and parents regarding barriers and facilitators associated with achieving the recommended amount of physical activity both at school and at home.

\section{Acknowledgements}

None.

\section{Conflict of interest}

The author declares no conflict of interest.

\section{References}

1. Centers for Disease Control and Prevention (CDC). Youth Risk Behaviors Surveillance - United States, 2009. Mobility and Mortality Weekly Report. 2010;59(SS-5):1-142.
2. United States Department of Health and Human Services (USDHHS) Healthy people 2020. USA: US Department of Health and Human Services; 2010.

3. Sturm R. Childhood obesity-what we can learn from existing data on societal trends, part 1. Preventing Chronic Disease. 2005:2(1).

4. American College of Sports Medicine. Physical activity guidelines.

5. Kahan D. Recess, extracurricular activities, and active classrooms: Means for increasing elementary school students' physical activity. Journal of Physical Education, Recreation \& Dance. 2008;79(2):26-31.

6. Story M, Nanney MS, Schwartz MB. Schools and Obesity Prevention: Creating School Environments and Policies to Promote Healthy Eating and Physical Activity. Milbank Q. 2009;87(1):71-100.

7. Butterfoss FD, Kegler MC, Francisco VT. Mobilizing organizations for health promotion: Theories of organizational change. In: Glanz K, et al. editors. Health behavior and health education: Theory, research and practice. 4th ed. USA: Jossey-Bass; 2008. p. 335-361.

8. Steckler A, Ethelbah B, Martin CJ, et al. Pathways process evaluation results: a school-based prevention trial to promote healthful diet and physical activity in American Indian third, fourth, and fifth grade students. Prev Med. 2003;37(6 pt 2):S80-S90.

9. Kaur H, Hyder ML, Poston WS. Childhood overweight: An expanding problem. Treat Endocrinol. 2003;2(6):375-388.

10. Vann JCJ, Finkle J, Ammerman A, et al. Use of a tool to determine perceived barriers to children' healthy eating and physical activity and relationships to health behaviors. J Pediater Nurs. 2011;26(5):404-415.

11. Baskin ML, Zunker C, Worley CB, et al. Design and implementation of a pilot obesity prevention program in a low-resource school: Lessons learned and research recommendations. Health Education. 2009;109(1):66-85.

12. Cothran DJ, Kulinna PH, Garn AC. Classroom teachers and physical activity integration. Teaching and Teacher Education. 2010;26(7):13811388 .

13. Evenson KR, Ballard K, Lee G, et al. Implementation of a school-based state policy to increase physical activity*. J Sch Health. 2009;79(5):231238 .

14. Gaus MD, Simpson, Cynthia G. Integrating physical activity into academic pursuits. Kappa Delta Pi Record. 2009;45(2):88-91.

15. Story M, Kaphingst KM, French S. The role of schools in obesity prevention. Future Child. 2006;16(1):109-142.

16. Franks AL, Kelder SH, Dino GA, et al. School-based programs: Lessons learned from CATCH, Planet Health, and Not on Tobacco. Prev Chronic Dis. 2007;4(2):A33

17. National Association for Sport and Physical Education. Georgia: State physical education profile; 2010 